\title{
Estudios de recorridos religiosos: los desafiliados en contexto
}

\author{
Dra. Véronique Lecaros \\ Pontificia Universidad Católica del Perú
}

\section{Resumen:}

El objetivo de este artículo es analizar la desafiliación como parte de un proceso religioso. Los estudios sobre afiliación, conversión y desafiliación (deconversión) muestran que los cambios religiosos no ocurren de manera arbitraria. Henri Gooren desarrolla un valioso esquema para dar cuenta de este proceso de cambios que llama "recorridos de conversión". Sin embargo, reconoce que le faltan casos latinoamericanos para confirmar la validez de su teoría en la zona. En este artículo, examinamos su propuesta y confrontándola con algunos casos limeños sugerimos ajustes.

Consideramos que el esquema tiene sentido en contexto evangélico de denominaciones y que puede también aplicarse a los movimientos eclesiales católicos. Sin embargo, el recorrido de conversión obvia dos fenómenos importantes: por una parte, la tendencia moderna a la desinstitucionalización que significa asumir autonomía con respecto a las instituciones religiosas sin ruptura clara, es decir sin desafiliación y por otra parte, el tradicional catolicismo cultural que corresponde a prácticas religiosas en las cuales la institución juega un papel segundario.

Palabras claves: desafiliación, recorrido de conversión, Perú, religión y cultura

\section{Abstract}

Our purpose is to study disaffiliation as a step in a religious process. The literature on affiliation, conversion and disaffiliation (deconversion) shows that religious changes do not happen at random. Henri Gooren develops a valuable pattern to match this process of changes which he calls "conversion careers". Nonetheless, he admits that he has at his disposal very few Latin-American life stories to confirm his theory. In this article, we analyze Gooren's theory and suggest a few changes based on some Limenian cases. We consider that Gooren's pattern can be applied in a denominational protestant context and is useful to interpret catholic ecclesial movements. Nonetheless, the conversion career does not take into account two important phenomena: on the one hand, the modern tendency to deinstitutionalization which implies autonomy from religious institutions without a clear break, I.E. without disaffiliation and on the other hand traditional cultural Catholicism which corresponds to religious practices in which the institution plays a secondary role.

Keywords: disaffiliation, conversion career, Peru, religion and culture 
Hace apenas medio siglo, el paradigma de la secularización dominaba en las ciencias sociales esperándose el triunfo de la razón científica y con ello, según la expresión de Max Weber, el "desencanto del mundo". Este vaticinio no se realizó y hoy sociólogos y antropólogos han abandonado la teoría. Peter Berger, quien asumió en sus primeros años la convicción del triunfo de la secularización, concluye después de cuestionarse a sí mismo: "me demoré varios años para llegar a la conclusión que la teoría de la secularización es empíricamente invalida" (Berger, 2014: p.19).

Sin embargo, a pesar de que el mundo sigue encantado, en particular en América Latina (Marzal, 2002; Romero, 2013; Morello, Romero, Rabbia, Da Costa, 2017), la categoría de "sin religión" representa uno de los grupos que más crece. El reto consiste entonces en pensar lo que puede parecer antagónico: el encantamiento y la desafección de la religión. Tomando en cuenta que el término de religión es per se polisémico, el de "sin religión" lo es con mayor razón ${ }^{1}$.

Más allá de la referencia al ateísmo o al agnosticismo, la terminología para referirse a los "sin religión" es múltiple: sin religión, no religión, desafiliación, no afiliación (con las variantes cristianas frecuentes en EEUU, unchurched, dechurched), deconversión, apostasía (Currie, 2016: p.50)... Como lo nota Heinz Streib, hablando desde una perspectiva europea y norteamericana, la investigación sobre lo que él llama "deconversión” empezó muy recientemente y sin desarrollarse de manera sistemática (Streib, 2014: p.274). El diagnóstico de Streib se aplica con mayor razón en América Latina donde el fenómeno recién empieza a cobrar importancia y a ser observado.

Nos proponemos en el marco de este artículo abordar el tema de los "sin religión" en Lima, en contexto, es decir como un aspecto de un fenómeno más amplio de múltiples alternativas religiosas que implican una posibilidad de cambio de pertenecía religiosa ${ }^{2}$. El campo religioso hoy no es estático: la movilidad se ha vuelto una de sus características. El encontrarse

Como lo afirman Anne Levallois y Dominique Iogna-Prat (2010: p.1028), "la noción de religión es una creación occidental reciente que se produce al inicio de la modernidad". Precisan que la religión se vuelve un tema genérico solamente a partir del siglo XIX, paradójicamente cuando la "secularización del pensamiento" lleva a distinguir lo eclesial y lo religioso de las sociedades pensadas como autónomas.

2 En otro artículo de esta revista, Catalina Romero y yo hemos presentado un artículo que analiza los desafiliados, es decir los ateos y los "sin religión" pero en este artículo me propongo abordar la desafiliación en contexto, es decir como una eventual etapa en un proceso. 
sin afiliación religiosa corresponde entonces a una etapa transitoria o definitiva en un recorrido que se despliega a lo largo de una vida.

En la mega urbe de Lima, la modernidad con su pluralidad diversa es un fenómeno relativamente nuevo (Romero, 2016: p. 14). Hasta finales de los 1980, la religión católica, como lo revelaban los censos, era hegemónica: comprendía más del 95\% de la población. En el siglo XXI, tal como lo arrojan el censo de 2007 y las encuestas (WV, Pew, Latinobarometro), los fieles de otras religiones y los sin religión representan una minoría significativa, entre un quinto y un cuarto de la población. Se ha vuelto imposible no codearse con personas de otras religiones e inclusive con personas que, pertenecientes a una misma religión, la viven de otra forma. Frente a la multiplicidad de opciones, las personas conocen otras religiones, visitan otros templos y en algunos casos, deciden cambiar de religión. Berger ha propuesto en su último libro considerar la pluralización como el nuevo paradigma del campo religioso que ofrece al ser humano la posibilidad de (no)adhesión voluntaria a grupos religiosos : "La modernización implica una gran transformación en la condición del ser humano de la fatalidad a la elección” (Berger, 2014: p.5)³.

Los autores que han estudiado la movilidad religiosa han observado que esta no ocurre de manera aleatoria, sino que se pueden discernir probables recorridos por los cuales transitan la mayoría de los fieles. Existen dos temáticas en este campo. Por una parte, algunos autores analizan los cambios desde el punto de vista de las instituciones eclesiales. Si la conversión del catolicismo al pentecostalismo es frecuente, lo opuesto es excepcional (Cleary, 2004; Frigeiro, 2007: p.45). Además en el campo de las Iglesias evangélicas ${ }^{4}$, también existe un recorrido que siguen la mayoría de los fieles: como lo mostró Uta Ihrke, en Lima, varios miembros de las Iglesias pentecostales (como por ejemplo Asambleas de Dios) transitan hacia Iglesias neo-pentecostales pero lo opuesto

\footnotetext{
3 Analizando los resultado de la encuesta del Pew Research Center (2008) sobre la movilidad religiosa en EEUU y en Europa. Los sociólogos José Casanova (2013: p.117) y Heinz Streib (2014: p.277) han notado la diferencia entre ambas zonas. Como lo expresa Casanova, incluyendo a los que han cambiado de pertenencia institucional en el ámbito protestante, "la cantidad de adultos que han cambiado de afiliación religiosa se eleva a $44 \%$. Es un fenómeno totalmente incomprensible en el contexto europeo donde el único cambio relevante es "unchurching" (abandono de la Iglesia) y secularización confesional". En América Latina y en particular en el Perú, aunque no se tenga datos tan precisos, las encuestas y los censos surgieren que los cambios religiosos individuales se asemejan a los que ocurren en EEUU, pero en menor proporción.

4 En este artículo, empleamos la noción "evangélico" a la usanza peruana para designar a todos los cristianos no católicos.
} 
rara vez ocurre (Ihrke, 2014; 2016). Por otra parte, se pueden también discernir caminos de conversión en el seno de las Iglesias que implican un progresivo aumento de involucramiento en asuntos eclesiales que pueden acabar en un abandono total de la comunidad (Gooren, 2007; 2010; Streib, 2014). Entre los especialistas, se debe destacar Henri Gooren quien ha sistematizado la teoría del recorrido de conversión para interpretar los resortes de la evolución personal en una institución eclesial. Gooren nota que faltan historias de vida para poder entender la dinámica del recorrido en América Latina, especialmente de personas que no sean (o no hayan sido) líderes religiosos (2010: p.69).

Gracias a una investigación financiada por la Templeton Foundation, tenemos a nuestro alcance 80 historias de vida de limeños que se identifican con varias religiones ${ }^{5}$. Nuestro objetivo es confrontar la teoría de Gooren a la narrativa de algunos de nuestros entrevistados.

Después de presentar brevemente la teoría de Gooren, mostramos cómo permite dar cuenta de historias de vida primero en el ámbito evangélico y segundo en el contexto católico. En ambos casos, consideramos la posibilidad de ajustes al modelo de Gooren a partir de la idiosincrasia peruana. Se debe tomar en cuenta que los desafiliados como los designa Gooren, no constituyen una categoría universal que ostenta las mismas características en todas las culturas.

\section{Presentación del recorrido de conversión y desafiliación según Gooren}

Hasta hace poco, la conversión religiosa se había pensado tomando como modelo, la conversión de Pablo que se asocia a un evento único de encuentro con Dios provocando un cambio profundo en la vida de la persona y en la manera en la cual ella se identifica y se ubica en relación a los demás (Frigeiro, 2007: p.41) ${ }^{6}$. Sin embargo, este paradigma -según la expresión de

\footnotetext{
5 La investigación mencionada está dirigida por Gustavo Morello de Boston College y se realiza en Lima, Montevideo y Córdoba, y ha sido financiada por la Fundación J.F. Templeton. Los investigadores principales son Catalina Romero, Néstor Dacosta y Hugo Rabbia en cada ciudad, y en Lima, han participado como co-investigadores Rolando Pérez y Veronique Lecaros.

6 Para entender cómo se formó el paradigma de conversión "pauliniana”, el estudio histórico de Michel Fattal (2017) es muy esclarecedor. El autor analiza cómo la conversión de Pablo es el fruto de la doble herencia griega y hebrea. Algunos elementos como la luz y por ende la renovada comprensión de la Verdad se originan en los filósofos platónicos mientras que otros como la iniciativa divina al origen del proceso y el arrepentimiento del sujeto, provienen del judaísmo.
} 
Frigeiro- que orienta definitivamente una existencia no permite dar cuenta de los múltiples cambios por los cuales ahora transitan los fieles en el curso de sus vidas.

En el contexto latinoamericano, el cambio de Iglesias calificado por algunos de "nomadismo" es frecuente (Uribe, 2009: p.185; Bastian, 2001: p.106). Los líderes religiosos suelen expresar la dificultad para retener a los fieles que se acercan a sus Iglesias: a pesar de su entusiasmo inicial, muy pocas personas perseveran. En entrevistas personales, algunos pastores nos comentaron que calculan que casi $75 \%$ de los que entran en sus Iglesias se alejan al cabo de pocos meses (Lecaros, 2015a: p.87; ver también sobre el fenómeno en el ámbito mormón, Bryant, Gooren, Phillips, Stewart, 2014: p. 773). La noción de conversión no permite entonces interpretar el movimiento inter-religioso.

Para dar cuenta de los diversos matices involucrados en las diferentes formas de adhesión religiosa institucional, Gooren desarrolla un circuito complejo que designa como recorrido de conversión (“conversion career") (Gooren, 2010: p.48; Currie, 2016: p.55) 7. Gooren se inspiró en el pastor protestante y psicólogo Lewis Rambo quien desarrolló un modelo dinámico del proceso de conversión que se inicia por una crisis en el individuo y su consecuente búsqueda de solución. Rambo en el proceso toma en consideración tres parámetros con sus derivados: la afiliación (desafiliación que llama apostasía), la intensificación (o alejamiento) y, el cambio de tradición o de institución. Gooren, a partir de este esquema dinámico formula su propia teoría.

En la situación de pre-afiliación, ocurren los primeros contactos entre el eventual afiliado y la institución. La persona asiste a los cultos pero no se identifica con la enseñanza de la Iglesia. En términos eclesiales, los líderes llaman a estas personas, "visitantes". En el medio evangélico, se suele dar una especial atención a estas personas, saludarlas con afecto, rezar por ellas, pedir sus datos para buscarlas (Lecaros, 2016a: p.98).

La afiliación corresponde a un paso importante aunque no determinante en la vida del fiel. La persona se vuelve un miembro formal, inscrito y eventualmente bautizado. A diferencia de la pre-afiliación, el miembro desarrolla la costumbre de frecuentar la comunidad, sin embargo, su estilo de vida no cambia radicalmente.

Gooren afirma haber usado un término de James Richardson aunque haya desarrollada otro tipo de propuesta (Gooren, 2014: p. 110). Cabe recalcar que la noción de recorrido está muy enraizada en el cristianismo, religión llamada inicialmente, el "camino". Teresa de Avila sistematizó un recorrido de fe. 
La conversión -en el sentido limitado de un momento en el recorridocorresponde a una etapa en la cual la persona se transforma y asume una nueva identidad. La relación con la Iglesia ocupa un lugar formativo y de primer plano en su vida. En términos eclesiales, se considera a este miembro "converso", un miembro activo que cumple con las normas de vida propugnada por la Iglesia (típicamente: asistir al culto, diezmar, castidad, normas alimenticias).

La confesión implica asumir ciertas responsabilidades en el seno de la Iglesia. En general, la persona actúa como representante de su Iglesia y desarrolla actividades proselitistas. Según sus capacidades, la persona también puede ejercer funciones de formadora. En este grupo se ubican los líderes, los misioneros...

Los desafiliados son los que se han alejado de la Iglesia y no se involucran en sus actividades. Las personas pueden haber pedido ser tachadas de las listas de membrecía pero en general, en el Perú, dejan de participar sin notificación.

Gooren subraya que uno de los aportes de su perspectiva corresponde a la distinción entre afiliación y conversión: una persona puede participar regularmente de una Iglesia pero no sentir mayor compromiso con ella al punto de tratar de adecuar su modo de vida a las normas de la Iglesia. El cambio personal ocurre a partir de la conversión y por supuesto de la confesión.

En una entrevista, se puede notar la asimilación de los parámetros de la Iglesia hasta en la apropiación del vocabulario. En la forma de hablar de varios evangélicos de grupos conservadores y fundamentalistas, se nota la influencia del estilo de la Biblia que leen en la versión antigua de la Reina Valera. Por ejemplo, en vez de hombre, usan la palabra varón y hasta designan a las mujeres como "varonas". En este sentido, el gran aporte de Gooren consiste a tomar en cuenta el factor tiempo. Varios autores han notado la importancia de un proceso a veces muy largo de asimilación de la conversión (Lecaros, 2016a: p.81; Aubrée, 2002: p.53; Pérez Guadalupe, 2002: p.329 ; Marzal, 1988: p.418)

\section{Aplicación del recorrido de conversión a casos de evangéli- cos limeños}

A partir de algunos casos, nos proponemos confrontar el diagrama de Gooren a historias de vida limeñas. Se trata de evaluar la pertinencia de este esquema y eventualmente considerar algunas modificaciones para adecuarlo a la realidad peruana. 
El caso de Moisés: dentista, 38 años, casado, padre de familia (3 hijos), de origen provinciano muy pobre, evangélico. La familia de origen de Moisés era evangélica pero él estudió en colegio católico y se acuerda que a los 11 años se sintió católico. "Yo supuestamente era católico porque en esa época, iba a la iglesia, me persignaba... [...] iba a las misas de gallos a las 5 de la mañana". Añade: "a los 11 años, definitivamente, decidí ya no ir a la Iglesia evangélica, me pegue a la Iglesia católica”. Sin embargo, Moisés nunca fue bautizado en la Iglesia católica, el colegio no se lo exigía.

En la universidad, Moisés se aleja de la religión por cuestionar la creación divina tal como está presentada en el Génesis: “yo me había hecho prácticamente ateo, pero con esto del origen de la vida, de la explosión, del Big Bang y todo lo demás y uno cree que realmente no eres producto de la creación de Dios"».

Después de una fuerte crisis matrimonial, Moisés "tiene un encuentro con Dios" y "empieza a sentir la ayuda de Dios de una forma sobrenatural". Después de probar varias Iglesias (2 años de diversos intentos), se queda con la Iglesia Evangélica Cristiana, de tipo pentecostal; en el momento de la entrevista tiene 11 años en ella. Moisés sigue las costumbres evangélicas a pesar de las críticas de su entorno (su mujer no es evangélica): aparte de las prácticas religiosas (leer la Biblia, asistir al culto...) no baila y no toma licor. En su forma de hablar, Moisés evidencia todos los modismos característicos del hablar de los evangélicos. Justifica sus posiciones o interpreta las situaciones a partir de referencias a la Biblia. Usa el vocabulario común a los evangélicos: "congregar" (participar en una Iglesia), "predicar la palabra" (hablar de Dios a partir de la Biblia), considera que Dios lo guía ("Dios me puso en esta Iglesia")...

Según el esquema de Gooren, Moisés se ubica en la fase conversión. Su convicción religiosa permea toda su vida, orienta sus relaciones con los demás en todo momento. Hasta la forma de tratar a sus pacientes se inspira en su fe, no solo porque eventualmente les "predica" sino porque no se aferra al cobro y no les pide adelanto. Si obviamos la niñez, el recorrido de Moisés sería desde la afiliación a la Iglesia católica (con una eventual fase de pre-afiliación en el colegio) a la desafiliación por ser "prácticamente ateo"

Aunque no podamos abordar el tema en este artículo, Moisés es un claro ejemplo de la forma en la cual el supuesto "conflicto" entre la lógica científica y la cristiana puede llevar algunas personas a la desilusión con la Iglesia "engañosa", a la desafiliación y hasta al ateísmo (Lecaros, 2016b). 
en el medio universitario seguido por una fase de búsqueda, entrada y salida en algunas Iglesias, hasta finalmente afianzarse en una Iglesia y llegar a la posición de converso por haber asimilado e integrado a su vida el discurso y perspectivas evangélicas. Para dar cuenta de este recorrido, debemos añadir una flecha de ida y vuelta entre desafiliación y pre-afiliación que corresponde a la fase de búsqueda en la cual la persona entra y sale de diversas Iglesias.

El caso de Katy (clase media, baja) de 23 años, estudiante, evangélica, pertenece a la Iglesia Asambleas de Dios, "Avanzando la Luz", fundada por su abuelos quienes fueron pastores, su papá también es pastor de aquella Iglesia. Katy ha recibido una educación evangélica y aunque hizo parte de su educación en colegios católicos donde tenía que asistir a misa y llegó a ser parte del coro, nunca se adhirió al catolicismo (a diferencia de Moisés). A los 20 años, tuvo un momento de "rebeldía" y se "apartó" de la Iglesia (menciona el agnosticismo). El hecho resultó de una suerte de crisis entre por una parte un enamorado ateo y por otra su familia que la presionaba. Finalmente, Katy dejó a su enamorado y a su familia y vivió sola. Y, a los 21 años, después de "encontrarse con Dios", regresó a la casa familiar y volvió a la Iglesia.

En el momento de la entrevista, su fe orienta su vida y su relación con los demás: sigue fielmente los mandatos de la Iglesia. Las expresiones que escoge para narrar su vida son las consagradas en el medio evangélico. Está buscando una forma de involucrarse aun más con la Iglesia. Así lo cuenta: "tengo un llamado muy fuerte al ministerio, a trabajar con jóvenes en la Iglesia pero todavía estoy como que buscando en qué cosa. No sé si todavía voy a ser o pastora o de repente voy a ser misionera pero hay un llamado ahí que todavía estoy descubriendo con Dios y obviamente orando y ya llegará en su tiempo". Esta manera de proceder, de orientarse, de tomar decisiones es propia de los pentecostales así como el vocabulario que emplea.

Según el recorrido de Gooren, Katy se inició en la fase afiliada por su familia y pasó a desafiliada. Desde allí, regresa a la Iglesia, o bien a afiliada o bien directamente a convertida. Por su educación familiar, ya estaba impregnada de la lógica evangélica. Este ejemplo muestra que se deben añadir flechas de regreso desde la desafiliación hasta la afiliación, conversión. Actualmente Katy se encuentra en la fase conversión, considerando pasar a la fase confesión.

El caso de Luciana, 42 años, diseñadora de moda, empresaria, clase alta (estudió en el Boston College), aunque eventualmente pueda tener problemas 
de dinero. Pertenece a la Iglesia neo-pentecostal Agua Viva. Luciana nace en una familia católica, de muchas devociones y practicante. Ella sigue la tradición familiar. Pierde al papa y al tío, y su hermana se casa. Luciana entonces siente un "gran vacío en su vida" que no logra llenar aun probando todo tipo de euforizantes y distracciones. A los 25 años teniendo un problema de exceso de bebida, fue llevada por una amiga a una Iglesia evangélica (Iglesia Cristiana de Camacho que aparte del culto dominical, tiene reuniones semanal en un hotel de lujo). Luciana empieza a seguir con asiduidad los cultos.

Su mama, asustada por su frecuentación evangélica, la manda al psiquiatra quien certifica que no es loca. Durante 3 años, frecuenta la Iglesia católica y la evangélica y estudia la Biblia. Durante este tiempo, se sigue identificando como católica. Sin embargo, su estilo de vida se transforma y los demás notan cambios en ella. A los 28 años, pide el bautismo evangélico. Se muda poco después a la Iglesia Agua Viva donde llega a ser líder y a predicar. Al cabo de unos años encuentra a un chileno con el cual se quiere casar. Este la presiona para dejar su Iglesia. Así expresa Luciana la situación: "estaba en pecado con el chileno". Abandona la Iglesia evangélica pero con mucho pesar, acompaña esporádicamente a su novio a la Iglesia católica pero sin convicción. Después de romper con su novio chileno, en gran parte -así lo interpreta- por tema de religión, regresa a Agua Viva. En el momento de la entrevista, tenía un año de regreso a la Iglesia.

A lo largo de tantos años, se desdibuja un recorrido complejo. Si consideramos solamente su paso por la Iglesia evangélica, tenemos el paso de la pre-afiliación a la afiliación y conversión que fueron casi simultáneas. El cambio de Iglesia podría tomar la forma de un pase por desafiliación seguido de un inmediato retorno a la fase afiliación, conversión. Según lo señalado líneas arriba, en Agua Viva, se vuelve líder y entonces pasa a la confesión. En el momento de su noviazgo con su enamorado chileno vuelve a la desafiliación y finalmente regresa a la fase conversión. En esta historia de vida también se evidencia la necesitad de añadir flechas de ida y vuelta de la desafiliación a todas las etapas menos a la confesión porque todas la Iglesias ponen a prueba a alguien que llega de la desafiliación.

\section{La desafiliación como una etapa}

Gooren no tenía a su disposición historias de vida latinoamericanas que permitan dar una perspectiva sobre varios años y estas tres narraciones muestran la necesidad de completar su esquema. Como lo nota Currie (2016: 
p.55), según Gooren, la desafiliación es un término al cual uno acaba desde todas las etapas del recorrido. Sin embargo, como lo han visto también otros autores (Barrera, 2014; Lecaros, 2015a ), la desafiliación es a menudo una etapa temporaria. Cabe también subrayar que esta etapa puede ser transitada varias veces en una vida, como en el caso de Luciana9. Proponemos entonces una corrección del esquema que incluya en la dinámica la desafiliación como una etapa. La única flecha sin vía de retorno se ubica entre confesión y desafiliación porque para ser reconocido como líder, el miembro necesita varios meses (años?) de pertenencia para ganar la confianza de los demás.

En la literatura europea sobre el tema (Streib, 2014; Stoltz, 2016; Gachet, 2013; Portier, 2012), la desafiliación es considerada como un estado sin salida o con salidas tan excepcionales que no se estudian como un fenómeno social. En este sentido, nos parece que Gooren, por lo menos en la articulación de su esquema, tiende a pensar a partir de la referencia europea. Podríamos preguntarnos si esta forma de abordar el tema no influye también sobre muchos pensadores latinoamericanos. Es significativo que en una encuesta hecha en Brasil sobre los cambios religiosos, una de las pocas sobre el tema (Frigeiro, 2007: p.45), no se considere que los "sin religión" puedan cambiar de situación ${ }^{10}$.

El esquema de Gooren permite visualizar la lógica de los cambios religiosos. Sin embargo, el esquema tiene limitaciones de los cuales hay que tener consciencia para aprovecharlo de manera adecuada. Enfoca los cambios religiosos desde el punto de vista institucional y por lo tanto, no da plenamente cuenta de la perspectiva subjetiva y de sus matices, en particular la borrosidad de las identificaciones. Luciana afirma que se seguía considerando católica

9 En este análisis, no tomamos en cuenta la figura del buscador ("seeker") que conscientemente va cambiando de Iglesias. En los casos presentados, el recorrido es la resultante de cambios ocurridos en su vida.

10 Cabe recalcar que en una encuesta que se hizo como parte de las investigaciones de doctorado de Uta Ihrke (2014), se preguntó a los evangélicos si habían cambiado de Iglesias. Una ínfima minoría afirmó haberlo hecho. El resultado se puede explicar por la dificultad a cuantificar el fenómeno (así se explicó en el grupo de investigación SIER donde se analizaban los resultados) pero también podría entenderse de otra manera. En los 3 casos analizados, es posible que ninguno considere haber cambiado de Iglesias. Katy regresó a la misma. Moisés después de probar varias Iglesias sin llegar a mayor compromiso, entró en una y allí se ha quedado. Luciana nunca llegó a entrar plenamente en la Iglesia de Camacho, en cambio en Agua Viva se formó y percibe a la Iglesia como su familia. A la postre, quizás, muchas personas no perciben sus pasos por otras Iglesias como un cambio sino como parte de una búsqueda hasta encontrar el lugar afín. 
durante los 3 años que frecuentó el grupo neo-pentecostal. Sin embargo, a los ojos de los demás había cambiado, incluso ella misma reconoce que su estilo de vida no era el mismo. Ella entonces durante este tiempo se ubicaba sobre 3 etapas y 2 Iglesias: pre-afiliada a una Iglesia evangélica, afiliada a la Iglesia católica y en proceso avanzado de conversión en una Iglesia evangélica.

El esquema de Gooren supone una forma de objetividad pero en las narraciones personales, tal objetividad no existe, más bien se pide al entrevistado contar sus experiencias de la manera más personal posible. Los investigadores son a menudo los que aplican estas categorías al relato. De hecho, los entrevistados presentan una interpretación de su vida a partir de los parámetros que se han vuelto los suyos pero que no necesariamente lo eran en el momento de los eventos. Además, como lo nota Hervieu-Léger (1999: p.131), los "relatos de conversión" tienden a ser muy conformista y no se caracterizan por su originalidad. Funcionan como moldes en los cuales Nolens Volens, el fiel formatea su vivencia y la transforma en un cuadro interpretativo que da sentido a toda su vida ${ }^{11}$. A menudo, el relato tiende a tomar la forma de una justificación de los eventos a partir de una finalidad que solamente se logra descubrir a posteriori' ${ }^{12}$. Nancy Ammerman (2014a; 2014b: p.105) insiste sobre la importancia del discurso para afianzar la fe y formar comunidades. Ammerman afirma: "las personas que tienen el sentido de los sagrado más fuerte no son solamente los que participan frecuentemente en cultos sino los que se involucran en actividades religiosas que implican conversaciones y relaciones interpersonales". Katy, Moisés y Luciana interpretan su(s) fase(s) de desafiliación a partir de su posición de persona afianzada en la Iglesia y hacen uso del vocabulario consagrado (Lecaros, 2015a). Perciben aquel momento de manera muy negativa pero si hubieran sido entrevistados en otros momentos, el discurso seguramente hubiera sido diferente.

11 Paul Ricoeur ha mostrado la importancia del relato en la constitución de la identidad. Juega un papel particularmente importante en la constitución y toma de consciencia de la personalidad ("caractère"), el "idem" de la persona a la cual se incorpora el "ipse", es decir las diferentes identificaciones (1990: p.146).

12 Frigeiro (2007: p.43) considera que el uso exclusivo de relatos limita mucho el entendimiento de la evolución religiosa porque la persona interpreta a partir de su situación en el momento de la entrevista. En este sentido, el método longitudinal desarrollado por Streib et alii permite superar parcialmente estas limitaciones. Streib y su equipo han entrevistado con un intervalo de 10 años a personas que han dejado los testigos de Jehovah. Como Streib lo menciona en su ponencia de la SSSR en Washington (2017), la desazón inicial que se expresaba en la primera entrevista se ha mitigado mucho en la segunda entrevista. 


\section{Aplicación del recorrido a casos de católicos limeños}

Gooren aplica también su esquema a los católicos y analiza las diferentes fases (2010: p.120-129). Gooren tiene exclusivamente a su alcance católicos carismáticos. Ciertamente, como lo nota Gooren, el recorrido de estos católicos se parece al de los pentecostales, de hecho espiritualmente el movimiento carismático tiene raíces pentecostales y sigue asemejándose a él (Lecaros, 2016d: p.207). Gooren observa que pentecostales y carismáticos expresan sus conversiones en términos similares pero no la conceptualizan de la misma manera. "Para los pentecostales, la conversión se produce en el momento en el cual han aceptado a Jesús Cristo como su Salvador [...]. Para los carismáticos católicos, la conversión corresponde con el momento en el cual toman plena conciencia del amor de Dios para ellos" (Gooren, 2010: p.120). Para Gooren, los católicos desafiliados son los "católicos nominales" que nunca o muy rara vez se acercan a una iglesia (Lecaros, 2016c). En este caso, el circuito se inicia en el catolicismo nominal y se desarrolla en el ámbito del catolicismo carismático. Finalmente, algunos dejan el movimiento para volver a ser católicos nominales.

La aplicación del esquema de Gooren no se debe limitar a los católicos carismáticos. Permite también dar cuenta de la forma en la cual los católicos entran progresivamente en otros movimientos de la Iglesia católica, se adhieren al estilo de culto y de vida en general de estos grupos y algunos eventualmente los dejan para volver a la matriz inicial.

Caso de Eduardo, un estudiante de 20 años, proviene de una familia católica poco practicante que mantiene sin embargo una devoción a san Antonio. En la segundaria, Eduardo conoce al movimiento conservador Sodalite (Movimiento de Vida Cristiana) cuyos líderes lo preparan para el sacramento de la confirmación. Al entrar en el movimiento, se aferra a una práctica rigurosa de los sacramentos, frecuenta de manera asidua el grupo ("va todas las semanas para acercarse más a Dios") y sigue las normas del movimiento ( en referencia a evitar el pecado, "Seguíamos las reglas", señala). Su familia no lo entiende y lo considera un "marciano". Eduardo llega a ser un líder de jóvenes, animador de confirmación. La vida de Eduardo cambia al entrar en la universidad. Se aleja del movimiento (se vuelve un "echado", expresión consagrada por los sodalites). Eduardo considera que se ha vuelto un "católico light" (no asiste sino excepcionalmente a misa), por problema de "lujuria". Varias veces en la entrevista, asocia su estado actual a la "vergüenza". El recorrido diseñado por Gooren corresponde a las diferentes 
etapas del tránsito de Eduardo por el movimiento Sodalite desde una fase de pre-afiliación hasta llegar a la confesión como líder en el movimiento y finalmente la desafiliación.

Al caso de Pedro (27 años, asalariado) que llegó a ser catequista, también se le podría aplicar el esquema de Gooren. Pedro recibió una invitación para involucrarse en la pastoral de parte de sacerdotes filipinos salesianos. Llegó a ser catequista pero tuvo que dejarlo porque consideraba que no había coherencia entre su vida y lo que predicaba: "la regla de oro es la coherencia entre lo que tú predicas y entre lo que tú haces. [...] Mejor ahí dar un paso al costado y tal vez volver cuando te pongas a arreglar tu vida". Pedro añade: "lo más difícil es la castidad que te pide la Iglesia católica". Además, cuenta que por encargo de sus jefes en su trabajo, ha tenido en algunas oportunidades que mentir. Pedro mantiene todavía una práctica católica regular, misas semanales y algunas devociones con su familia. El esquema de Gooren corresponde al episodio como catequista, desde el progresivo involucramiento y formación hasta la confesión y finalmente la desafiliación.

Más allá del cristianismo (o denominaciones afines como mormones, adventistas y testigos de Jehovah) el esquema de Gooren puede exitosamente aplicarse a la adhesión a grupos vinculados a tradiciones religiosas que demandan a sus miembros una decisión personal y un estilo de vida particular. Entre nuestros entrevistados, figura Arie peruano judío (45 años). Proviene de una familia "no muy practicante", culturalmente vinculada a Europa Central. Decide con su esposa, a raíz de su matrimonio ser "consistente" y "cumplir con las normas religiosas" volviéndose así un judío ortodoxo. Hoy, Arie es certificador oficial cácher para la pequeña comunidad judía peruana. En la entrevista, Arie cuenta cómo progresivamente, su esposa y él fueron cambiando su estilo de vida, adecuando su casa a las exigencias cácher. En las celebraciones del Sabbat, Arie tiene que marcar distancia con su familia de origen que no practica con la misma rigurosidad que él. El recorrido de Arie por la ortodoxia judía corresponde al esquema de Gooren que tiene el merito de poner en relieve la importancia del factor tiempo y el progresivo cambio de estilo de vida ("habitus" en el sentido de Bourdieu). Después de una decisión personal y concertada con su pareja (vivir las exigencias del judaísmo ortodoxo puede solamente hacerse en familia), Arie llegó al momento de la confesión. Los términos de Gooren son cristianos pero se podrían encontrar expresiones más generales para adecuarse a estos procesos. 


\section{De la desinstitucionalización}

El esquema de Gooren aborda la religión desde la perspectiva institucional, lo cual no permite expresar con matices la manera de pertenecer y de vincularse a una institución, en otras palabras, no le permite tomar en cuenta la desinstitucionalización, el "beleiving without belonging", según la expresión famosa del sociólogo británico Grace Davie (Davie, 1994). Hervieu-Léger considera que en Europa en general se manifiesta en los creyentes una "predisposición" para este tipo de actitud (Hervieu-Léger, 2004: p.166). En América Latina también está ocurriendo el mismo fenómeno. Mallimaci menciona un "proceso de individualización religiosa y de desapego de las instituciones religiosas" (Mallimaci et al., 2015: p.261). Christian Parker y Catalina Romero aplican la expresión "católico a mi manera" a la realidad chilena y peruana (Parker, 2009: p.153; Romero, 2009: p.377). Renée de la Torre, a partir de un análisis del New Age llega también a conclusiones similares (de la Torre, 2016).

Desde la conversión, se puede desarrollar un proceso alternativo al circuito, confesión y/o desafiliación, que implique un distanciamiento de la institución ${ }^{13}$. Este proceso ocurre entre personas cuya fe ha madurado y que entonces han pasado cierto tiempo (varios años a veces) en una Iglesia. Al vivir en una ciudad como Lima donde domina el pluralismo en todos los campos, el fiel está expuesto a otros estilos de vida, otras realidades y otras maneras de entender la fe ${ }^{14}$. Como lo expresa Berger (2014: p.9), "el pluralismo relativiza y entonces socava muchas de las certidumbres con las cuales los seres humanos solían vivir".

Entre quienes han tomado distancia de las normas de sus Iglesias y viven su fe con más autonomía, algunos asumen plenamente su situación, otros mantienen un cierto pesar por la misma. Moisés es de los que vive una forma de autonomía sin cuestionamiento. Mantiene un estilo de vida pentecostal. Sus convicciones religiosas intervienen y permean toda su vida; sin embargo, asiste al culto solamente una vez al mes. No es un líder en su

13 Probablemente, Gooren no se percató de este fenómeno porque como lo afirma (2010: p.115), dispone de muy pocas historias de vida. Además principalmente, las narraciones a su alcance son de líderes jóvenes.

14 Conscientes del peligro que representan para las instituciones las verdades alternativas que lleva al relativismo, varios líderes evangélicos buscan conformar alrededor del creyente un círculo uniforme. Tratan de casar entre sí a los miembros de la Iglesia, de convertir a todas las familias, desarrollan actividades lúdicas e inclusive favorecen nichos de empleos (empresas de evangélicos que emplean a hermanos en la fe). 
Iglesia. Desarrolla una actividad en su cotidiano. Además, se desplaza para curar personas pobres gratuitamente en la selva.

Mario (58 años), chofer de taxi, se identifica como adventista. Viene de una familia católica y se convirtió en la adolescencia. En toda su entrevista regresa como leitmotiv su convicción de estar cerca de Dios: "yo siempre siento esta manifestación que el Señor no me abandona". Expresa también esta convicción con referencias bíblicas, como suelen hacerlo los adventistas conversos : "Yo estaré a tu diestra dice el Señor". En otro momento, Mario percibe que el Señor le dice: "no temas porque te haré caminar por campos obscuros"... Mario casi no asiste al culto del sábado, tampoco sigue las otras normas adventistas. Considera que esta situación no es correcta pero no merma su relación directa con Dios. Mario se piensa como un "instrumento de Dios" que ayuda y aporta alegría al prójimo. Desde el punto de vista de la institución, Mario sería considerado quizás como un desafiliado por los pastores adventistas pero él internamente mantiene su identificación. Pensando a partir del esquema de Gooren, lo más adecuado sería considerar a estas personas como conversas autónomas lo cual representa una alternativa a la desafiliación ${ }^{15}$. Estamos considerando el fenómeno de manera gradual y ciertamente, pueden existir casos pocos claros de persona desafiliada desde una perspectiva institucional y autónoma desde su propia comprensión subjetiva.

\section{Religión sin cultura versus religión "inculturada"}

El esquema de Gooren, con las modificaciones que hemos sugerido para ampliar su espectro de aplicación, da cuenta de los recorridos individuales de personas que emprenden un proceso de conversión en el seno de una institución eclesial escogida. A menudo, como lo hemos notado, esto implica una ruptura (a veces dolorosa) con el entorno. Varios expresan que fueron parcialmente rechazados por los suyos que no entendían su evolución. Las familias de Eduardo y Luciana se preocuparon por ellos y hasta por su salud mental. Katy en su fase de desafiliación y Moisés en su fase "católica" también suscitaban inquietud en sus familias.

Esta forma de abordar lo religioso implica una ruptura entre cultura y religión. Esta perspectiva se origina con el movimiento de la reforma. Como lo nota Olivier Roy, "la reforma afirma la disyunción absoluta entre

15 Entre este grupo, podríamos discernir muchos matices, los autónomos que asumen la distancia, los "enfriados" o los que han llegado a una práctica rutinaria (Roy, 2008: p.364, 365) y los desafiliados que han llegado a la ruptura. 
lo religioso y lo cultural" (Roy, 2008: p.91). Para Roy, la desconexión entre los marcadores religiosos y culturales implica el advenimiento de una religión sin cultura. Eduardo al entrar en el grupo sodalite deja de lado las tradiciones familiares, las menosprecia para seguir rigurosamente unas normas que su familia no entiende bien. Arie, al volverse un judío ortodoxo, también se aleja de las costumbres ancestrales.

El hecho que Gooren se refiera a grupos que funcionan como denominaciones, pentecostales, mormones y católicos carismáticos (muy cercanos en su espiritualidad al pentecostalismo) es sintomático de la dificultad de aplicar el esquema al ámbito católico tradicional latinoamericano ${ }^{16}$. Además Gooren, al estudiar el campo católico, considera como desafiliados a los católicos nominales que en realidad, nunca se auto-identifican como "sin religión" y que según la perspectiva institucional católica, siguen siendo católicos ${ }^{17}$.

Gooren no toma en cuenta la lógica propia del catolicismo tradicional que se afianza en devociones (Marzal, 2002). Entre nuestros entrevistados, han figurado varios católicos que como la mayoría de los católicos peruanos viven una fe heredada (a veces con modificaciones), mantienen varias devociones pero se acercan muy esporádicamente a la Iglesia (Lecaros, 2015b). No consideran que su relación con Dios pasa por obedecer estrictamente a normas ni tampoco por la mediación del clero. Rafael, un chofer de taxi de 42 años, va a misa cuando su esposa lo "obliga, la verdad" pero afirma "conversar con Él (Dios), como si de repente estuviera conversando con usted". Repite varias veces durante la entrevista: "creo mucho en Dios". Ha sido parte de la cofradía del Señor de los Milagros, la ha tenido que dejar

16 Gooren tiende a considerar que la inmensa mayoría de los católicos latinoamericanos son católicos nominales (2010: p. 126). Según el autor (2010: p.43), los católicos nominales en América Latina son "personas nacidas en el catolicismo que no han tenido y no tienen ningún tipo de compromiso con él”. Lo cierto es que la gran mayoría de los católicos acude excepcionalmente a la institución pero mantiene muy viva sus devociones y prácticas rituales cuyo origen se remonta a épocas pre-colombinas.

17 Según el derecho canónico que norma los criterios de pertenencia a la Iglesia católica, el sacramento de bautismo es indeleble (Lecaros, 2016c). En consecuencia, una persona bautizada sigue siendo católica a lo largo de toda su vida por más que ella no se considere como tal. Desde este punto de vista, el caso de Moisés es revelador. Nunca fue bautizado. Para la Iglesia no era católico pero él se sentía católico. Sin embargo, tuvo su fase de católico convencido durante la cual iba a misa regularmente. Cabe destacar para entender bien el caso que tradicionalmente, los peruanos no suelen comulgar, especialmente en el mundo rural o urbano marginal. Entonces, Moisés que no comulgaba no se sentía excluido como ahora los divorciados vueltos a casar europeos. El caso de Moisés es revelador de la necesidad de adaptar el esquema de Gooren a la lógica católica. 
porque no podía pagar la cuota pero sigue con la devoción. Esta forma de fe no implica recorrido en el sentido de Gooren. Sin embargo, no es uniforme, tiene momentos de gran intensidad, también implica reflexión ética. Rafael considera que por momentos se porta mal y que Dios se lo significa.

\section{Conclusión y reflexiones finales}

El marco teórico y el esquema propuestos por Gooren permiten dar cuenta de los procesos de conversión en denominaciones evangélicas o movimientos eclesiales católicos. Este implica varias etapas que van desde la aproximación a la Iglesia hasta el asumir cargos en el organigrama, pasando por el cambio de creencias y la adopción de un estilo de vida diferente. El proceso no necesariamente llega a culminarse y puede truncarse. El esquema pone en relieve la importancia de la maduración en el recorrido y por lo tanto el factor tiempo. Gooren disponía de pocas historias de vida y casi todas de líderes jóvenes. Aprovechando algunas de las historias de vida recolectadas en el marco de nuestra investigación, hemos propuesto algunos cambios que complementan el esquema y permiten ampliar su espectro de aplicación. Nuestro estudio muestra que la desafiliación, por lo menos en el ámbito peruano, no representa siempre un término en donde se acaba el recorrido, la aventura religiosa. A menudo, es una simple etapa transitada por algunos varias veces en el curso de sus vidas. Tenemos consciencia que se trata de una propuesta y que tampoco se puede pedir a un esquema cubrir todas las situaciones.

Sin embargo, queda una suerte de eje impensado en estos esquemas y quisiéramos mencionarlo para invitar a futuras reflexiones e investigaciones. Gooren menciona de manera critica la tendencia entre los investigadores en ciencias sociales a reducir la religión a factores socioeconómicos o psicológicos (2010: p.42). El esquema permite superar estas limitaciones pero no logra tomar plenamente en cuenta la percepción interior de la persona. Como toda propuesta objetiva, funciona etsi Deus non daretur, es decir como si Dios no interviniera, y pretende dar cuenta de un proceso sin mencionar la acción divina aunque la persona considere su historia como un encuentro con Dios buscado por Él. Internamente, la persona vive el proceso como una serie de hitos fuertes que corresponden a cada encuentro con Dios y que orientan su vida. Los considera como irrupciones del más allá (de un fuera de tiempo, eternidad, en el curso del tiempo ordinario). Sin prejuzgar si de hecho hubo o no encuentro con Dios, queda claro que estos hitos 
interpretados como manifestaciones de Dios están al origen del proceso de conversión y lo nutren. Juan Carlos Scannone quien ha desarrollado la "teología del pueblo", habla de una "mística del pueblo", expresión recogida por el Papa Francisco (Scannone, 2017, segunda parte). De hecho, varios de los entrevistados cuentan historias de encuentro con Dios similares a las de Pablo, Teresa de Ávila o John Wesley.

\section{Bibliografía}

Ammerman, N., (2014 a). Sacred stories, spiritual tribes, Oxford, Oxford University Press.

Ammerman, N., (2014 b). Response by Nancy T. Ammerman: modern altars in everyday life, in Berger, P.L., 1st ed. The many altars of modernity, toward a paradigm for religion in a pluralist age. Berlin, Boston, De Gruyter, pp.94-110.

Aubrée, M., (2002) Conflictos entre el discurso cristiano universalizante y el campo religioso fragmentador, in Masferrer, E., et alii, ed., Religión y postmodernidad, Quito Abya-Yala.

Barrera, P., (2014), Pentecôtismes culturels et pauvreté dans la périphérie urbaine du Brésil, in Tchonang, G., Lecaros, V., Sanchez, J., Le pentecôtisme, racines et extension, Afrique, Amérique latine, Paris, L’Harmattan.

Bastian, J. P., (2001) Pentecôtismes latino-américains, logiques de marché et transnationalisation religieuse, in J. P. Bastian, F. Champion, K. Rousselet, La globalisation du religieux, Paris, L'Harmattan.

Berger, P.L., (2014). The many altars of modernity, toward a paradigm for religion in a pluralist age. Berlin, Boston, De Gruyter, pp.1-93.

Bryant, S., Gooren, H., Phillips, R., Stewart, D., (2014) Conversion and retention in Mormonism, in Rambo, L., Farhadian, C., (ed.) The Oxford handbook of religious conversion, Oxford University Press. (p. 756-787).

J. Casanova, (2013) Religious associations, religious innovations and denominational identities in contemporary global cities, in I. Becci, M. Burchardt and J. Casanova, Topographies of faith, religion in urban spaces, Leiden, Brill.

Cleary, E., (2004) «Shopping around: questions about Latin American conversions », International Bulletin of Missionary Research, Vol. 28, N², April 2004.

Currie, S., (2016), Disaffiliation and new religious movements, in Lewis, J., Tollefsen, I., (ed.) The Oxford handbook of new religious movements, Oxford University Press.

Davie, G, (1994), Religion in Britain since 1945, Oxford, Blackwell;

Fattal, M., (2017), Conversion et spiritualités dans l'antiquité et au Moyen Âge, Paris, L'Harmattan.

Foerster, N., (2014) Les évangéliques de la Congrégation Chrétienne du Brésil en situation de grande vulnérabilité, in G. Tchonang, V. Lecaros, J. Sanchez, Le pentecôtisme, racines et extension, Afrique, Amérique latine, Paris, L'Harmattan. 
Frigerio, A., (2007) Analyzing conversion in Latin America: theoretical questions, methodological dilemmas, and comparative data from Argentina and Brazil, in Steigenga, T., Cleary, E., ed., Conversion of a continent, Contemporary religious change in Latin America, New Brunswick, Rutgers University Press, p. 33-52.

Gachet, C., (2013), Quitter le milieu évangélique, in Stolz, J., Favre, O., Gacher, C. and Buchard, E., Le phénomène évangélique, Analyses d'un milieu compétitif, Geneva, Labor et Fides, pp.257-279.

Gooren, H., Conversion careers in Latin America: entering and leaving Church among Pentecostals, Catholics and Mormons, in Steigenga, T. and Cleary, E., ed., Conversion of a continent, Contemporary religious change in Latin America, New Brunswick, Rutgers University Press, p. 52-72.

Gooren, H., (2010), Religious conversion and disaffiliation, tracing patterns of change in faith practice, New York, Palgrave, Macmillan.

Gooren, H., (2014), Anthropology of religious conversion, in Rambo, L., Farhadian, C., The Oxford handbook of religious conversion, Oxford University Press. (p. 84-117)

Hervieu-Léger, D., (1999), Le pèlerin et le converti, la religion en mouvement, Paris, Flammarion.

Hervieu-Léger, D., (2004), Individualism and the validation of faith, in Fenn, R., Sociology of religion, Oxford, Blackwell. (p. 161-176).

Ihrke, U., (2014) Religious mobility and social aspirations of Neopentecostals in Lima, Peru, Munster, LIT Verlag, 2014.

Ihrke, U., (2016) Movilidad religiosa y aspiración social en Iglesias neo-pentecostales de Lima, in C. Romero, Diversidad religiosa en el Perú, Miradas múltiples Perú, Lima, PUCP.

Lecaros, V., (2015a) Les sans religion en Amérique latine, Revue des Sciences religieuses, 89, $\mathrm{N}^{\circ} 1, \mathrm{pp} .83-104$.

Lecaros, V., (2015b), Los católicos y la Iglesia en el Perú. Un enfoque desde la antropología de la religión. in Cultura y Religión, Vol. 9, $\mathrm{N}^{\circ} 1$, Universidad Arturo Prat, Iquique, Nov. Available at http://www.revistaculturayreligion.cl/index.php/culturayreligion/issue/view/46 [accessed 21 jan. 2016]

Lecaros, V., (2016a), La conversión al evangelismo, Lima, PUCP.

Lecaros, V. (2016b) Las distintas caras de la secularización en Perú: la fragilidad del encantamiento religioso en la periferia, in Paulo Barrera (Ed.), Diversidade religiosa e laicidade no mundo urbano Latino-Americano, Curitiba, CRV.

Lecaros, V. (2016c), Evolución de la práctica de los sacramentos en Lima, in C. Romero, Diversidad religiosa en el Perú, Miradas múltiples Perú, Lima, PUCP.

Lecaros V., (2016d), La Iglesia Católica y el desafío de los grupos evangélicos, el caso del Perú en América Latina, Lima, Prensas Universitarias, Universidad Antonio Ruiz de Montoya.

A. Levallois, D. Iogna-Prat, (2010) Religion (Approche historico-philologique), in R. Azria, D. Hervieu-Léger, Dictionnaire des faits religieux, Paris, PUF. 
Mallimaci, F, Esquivel, J. C., Giménez Beliveau, V., (2015) What do Argentine people believe in? Religion and social structure in Argentina, in Social Compass, Vol. 62(2), p. 255-277.

Marzal M., (1988) Los caminos religiosos de los inmigrantes en la gran Lima, Lima PUCP. Marzal M., (2002) Tierra encantada, Lima, PUCP.

Morello, G., Romero, C., Rabbia, H., Da Costa, N., (2017), An enchanted modernity: making sense of Latin America's religious landscape, Critical Research on Religion. (p.1-19)

Parker, C., (2009) Education and increasing religious pluralism in Latin America: the case of Chile, in Hagopian, Frances ed., Religious pluralism, Democracy and the Catholic Church in Latin America, Notre Dame, University of Notre Dame.

Pérez Guadalupe, J. L., (2002), Ecumenismo, sectas y nuevos movimientos religiosos, Lima, Paulinas.

Portier, P., (2012) "Les mutations du religieux dans la France contemporaine", Social Compass 59 (2), 2012.

Ricoeur, P., (1990), Soi-même comme un autre, Paris, Seuil.

Romero, C., (2013) Por el encanto de una tierra, in Sánchez, J., Curatola, M., Los rostros de la tierra encantada, religión, evangelización y sincretismo en el Nuevo mundo, homenaje a Manuel Marzal, S.J., Lima, PUCP.

Romero, C., (2016) El Perú, país de diversidad religiosa, in Romero, C., ed., Diversidad religiosa en el Perú, Miradas múltiples, Lima, PUCP.

Roy, O., (2008) La sainte ignorance, le temps de la religion sans culture, Paris, Seuil.

Scannone, J. C., (2017), La théologie du peuple, Namur, Paris, Lessius.

Stolz, J., Könemann, J., Schneuwly Purdie, M., Englberger, T., Krüggeler, M., (2016) (Un) Beleiving in modern society; Religion, Spirituality, and religious-secular competition, Farham, Burlington, Ashgate.

H. Streib (2014), Deconversion, in Rambo, L., Farhadian, C., The Oxford handbook of religious conversion, Oxford University Press. (p. 271-296).

Torre de la, R., Martin, E., (2016) Religious studies in Latin America, Annual Review of Sociology, 42, pp 473-492.

Uribe, G., (2009), Les transformations du christianisme en Amérique Latine des origines à nos jours, Paris, Karthala. 